\title{
Universal approach of cellulose fibres chemical modification result analysis via commonly used techniques
}

\section{Stefan Cichosz ${ }^{1} \cdot$ Anna Masek $^{1}$ D $\cdot$ Korneliusz Wolski $^{1} \cdot$ Marian Zaborski $^{1}$}

Received: 3 April 2018 / Revised: 13 August 2018 / Accepted: 16 August 2018 /

Published online: 20 August 2018

(c) The Author(s) 2018

\begin{abstract}
This article considers the modification of cellulose fibres with the use of vinyltrimethoxysilane and maleic anhydride as substances to improve the wettability of the additive in the hydrophobic polymer matrix. The stress is put on the possible ways of modification impact investigation and its description. Effects of the treatment are analysed using Fourier transform infrared spectroscopy, which reveal the presence of new moieties on the cellulose surface, e.g. $\mathrm{C}=\mathrm{C}$ bonds, $\mathrm{C}=\mathrm{O}$ and $\mathrm{Si}-\mathrm{C}$ groups, while dynamic light scattering investigation revealed an increase in the hydrodynamic radii of the molecules which was maximized in the case of modification with the use of maleic anhydride. Furthermore, thermal properties were defined with differential scanning calorimetry and thermogravimetric analysis. Some variations within the process of samples thermal degradation are observed-thermal stability of the specimen modified with maleic anhydride is the highest. The presented approach of combined fibre modification analysis techniques, being a scientific novelty, allows to confirm the treatment impact on cellulose properties at many levels.
\end{abstract}

\section{Graphical abstract}

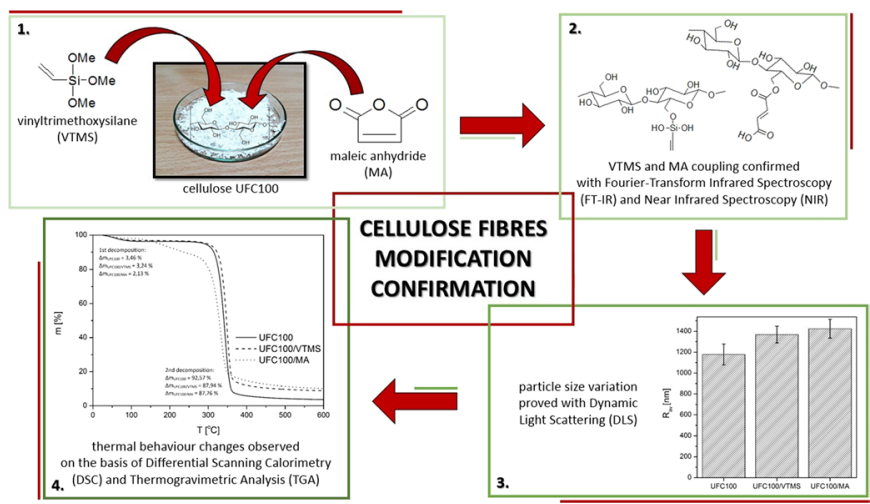

Keywords Cellulose $\cdot$ Maleic anhydride $\cdot$ Vinyltrimethoxysilane

Extended author information available on the last page of the article 


\section{Introduction}

Increasing interest in new materials from renewable resources and potentially environmental friendly methods for modifying such materials has led to increased interest in using cellulose [1]. Due to its abundance in the environment and its quick renewability as a biodegradable raw material [2], cellulose and its modifications have become a subject of research for many scientists. Cellulose exists in the cell walls of plants and can be produced by bacteria. It is a polysaccharide that is formed by the repeated connection of D-glucose building blocks, and it is characterized by specific properties that differ from other natural and synthetic polymers. Cellulose is distinguished by its hydrophilicity, biodegradability and broad chemical modification capacity [3]. The high hydrophilicity of the cellulose surface defines its behaviour in different media as well as its interactions with different chemicals. Adjusting the surface properties of cellulose is of great importance for its current and future applications, such as in papermaking and composites [4].

Various research papers have shown the great variety of properties that can be obtained through modifying the cellulose surface. The modification of plant fibres may involve removing the surface impurities, swelling the crystalline region and removing the hydrophilic hydroxyl groups. Effectively reinforcing composites with plant fibres depends on the moisture content, fibre-matrix interfacial adhesion [5], and crystalline and cellulose content. The alkalization of plant fibres improves their performance as a composite reinforcement [6]. Cellulose can also be chemically altered to increase its potential by making derivatives such as carboxymethyl cellulose, methyl cellulose, ethyl cellulose, hydroxypropyl cellulose and cyanoethyl cellulose [7]. Carboxymethyl cellulose (CMC) stands out among the stated derivatives; it is manufactured in significant amounts due to its wide commercial applications with regard to volume demands. It is used in many different industries, including food ingredients, pharmaceuticals and materials [8]. Such diverse applications along with its low pricing make $\mathrm{CMC}$ one of the major market shareholders within all the cellulose ether product categories [9].

Recently, ionic liquids (ILs) that have hydrogen bond acceptors in their structure, such as $\mathrm{Cl}^{-}, \mathrm{Br}^{-}$or $\mathrm{SCN}^{-}$, have been used to dissolve and process cellulose with great success [10-12]. These hydrogen bond acceptors are thought to be responsible for interrupting the extensive intermolecular and intramolecular hydrogen bonding within cellulose [13-15]. Due to the structure of cellulose, it is regarded as an active chemical. Functional groups can be introduced into the cellulose molecules through the hydroxyl moieties. New groups break the hydrogen bonding network in the cellulose, decrease the crystallinity and increase its solubility [16-19]. Ionic liquids have been used as a reaction medium for modifying cellulose using urea, phthalic anhydride (PA), maleic anhydride (MA) and butyl glycidyl ether (BGE). Previous experiments have shown that the hydrogen bonding interactions decrease and that anhydride groups have a higher reaction activity with hydroxyl groups [20].

Cellulose-based materials are easily obtained and can be employed as relatively cheap absorbents. They may also be used to remove heavy metal ions prior to the appropriate chemical treatment. Chemically modified cellulose materials present 
higher absorption capacities than unmodified forms. Modifications can be carried out in two ways. Monomer-grafting enables attaching many different functional groups to the backbone of cellulose. Another method of attaching new specific groups to the cellulose is direct modification in which new groups are bonded to hydroxyl groups through chemistries such as base solutions, mineral and organic acid solutions, organic compounds or oxidizing agents [21-23].

Despite development of new modification techniques, well-known compounds like silane coupling agents and various anhydrides are commonly used chemical modifiers. Due to their structure, they are able to form chemical bridges between cellulose fibres and the matrix. In various experiments, it was suggested that chemical reactions between cellulose and a coupling agent led to improvements in the mechanical properties of the composites. In spite of the fact that they are being commonly employed in cellulose modification, convincing evidence was not provided [24].

\section{Materials}

\section{Reagents}

The Arbocel ${ }^{\circledR}$ UFC100 Ultrafine Cellulose for Paper and Board Coating was the type of cellulose used for modification. It is in a powder form, nonmodified and insoluble in water. Simultaneously, this cellulose exhibits a high water binding capacity (even at high temperatures and shearing forces). Its average fibre length is $8 \mu \mathrm{m}$.

The first of the used modifiers was maleic anhydride (MA), otherwise known as 2,5-furanedione, provided by Sigma-Aldrich ${ }^{\circledR}$. It is a white solid substance with a molecular mass of $98.06 \mathrm{~g} / \mathrm{mol}$ and is commonly used in cellulose chemical modification. When dissolved in water, it turns into maleic acid. Its melting point is somewhere in the region of $51-56{ }^{\circ} \mathrm{C}$ (lit.) or $52-54{ }^{\circ} \mathrm{C}$. Furthermore, the fibres were also treated with vinyltrimethoxysilane (VTMS) U-611 from UniSil ${ }^{\circledR}$, which is a transparent, colourless liquid. In addition to being dissolvable in benzene, carbon tetrachloride and acetone environments also have the capability of reacting with water. All reagents were commercial products of the highest purity available, and their structural formulas are shown in Fig. 1.

\section{Methods}

\section{Chemical modification}

The cellulose was modified using vinyltrimethoxysilane (VTMS) and maleic anhydride (MA). In both cases, fibres were dried for $24 \mathrm{~h}$ at $70^{\circ} \mathrm{C}$, and then, the temperature was raised to $100{ }^{\circ} \mathrm{C}$ for an hour before performing the modification. 
Fig. 1 Structural formulas of (1) maleic anhydride (MA) and (2) vinyltrimethoxysilane (VTMS)
1)

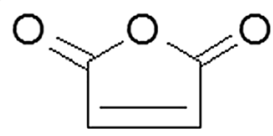

2)<smiles>C=C[Si](OC)(OC)OC</smiles>

As for the modification with maleic anhydride, the cellulose was treated in an acetone at room temperature for $2 \mathrm{~h}$ (oil bath $40{ }^{\circ} \mathrm{C}, 60 \mathrm{r} / \mathrm{min}$ ) using an evaporator. After stirring, the acetone was removed with a vacuum distillation process (oil bath $60{ }^{\circ} \mathrm{C}$, initial pressure 200 mbar). Then, the sample was heated in a vacuum oven at $100{ }^{\circ} \mathrm{C}$ and $170 \mathrm{mbar}$ for $4 \mathrm{~h}$ [25]. Figure 2 describes the maleinization process of the cellulose fibres with the creation of ester bonds on the surface of the filler.

Modification with the use of VTMS, the ethanol (used as a solvent), cellulose and silane were stirred, with the use of a rotary evaporator, in a flask for $4 \mathrm{~h}$ at $60 \mathrm{r} / \mathrm{min}$ (oil bath, $40{ }^{\circ} \mathrm{C}$ ). Then, the vacuum distillation (oil bath $60{ }^{\circ} \mathrm{C}$, initial pressure $200 \mathrm{mbar}$ ) was performed. After removing the solvent, the samples were dried for $24 \mathrm{~h}$ in a vacuum oven $\left(40{ }^{\circ} \mathrm{C}, 170 \mathrm{mbar}\right)$ and then for $48 \mathrm{~h}$ in a dryer at $120{ }^{\circ} \mathrm{C}$ [28]. Figure 3 presents the scheme of the silanization of the cellulose fibres with a focus on the successive stages of the chemical modification.

Such prepared powders were stored in a dryer at $40{ }^{\circ} \mathrm{C}$. In Table 1 , the conditions taken into consideration during all stages of both modifications processes are provided.

\section{Fourier transform infrared spectroscopy}

Fourier transform infrared spectroscopy (FTIR) absorbance spectra have been investigated within the $4000-400 \mathrm{~cm}^{-1}$ range which helped in assessing structural changes as each chemical group has its specific absorption band. The experiment has been performed with the use of Thermo Scientific Nicolet 6700 FTIR spectrometer ( $\mathrm{p} / \mathrm{n}$ 912A0637) equipped with diamond Smart Orbit ATR sampling accessory (p/n 840-145300).

\section{Thermogravimetric analysis}

Thermogravimetric analysis (TGA) has been used in order to get acquainted with thermal degradation process detecting the mass loss as a function of raising temperature in the range from 0 to $600^{\circ} \mathrm{C}$. Mettler Toledo ${ }^{\circledR}$ TGA/DSC 1 STAR $^{\mathrm{e}}$ System equipped with Gas Controller GC10 has been employed in this investigation.

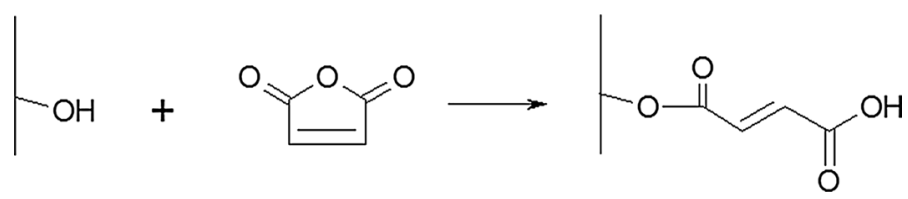

Fig. 2 Reaction scheme of the cellulose fibres with maleic anhydride [26] 
1)<smiles>C=C[Si](O)(O)C=CO</smiles>

2)<smiles>C=C[Si](O)(O)O</smiles>

3)

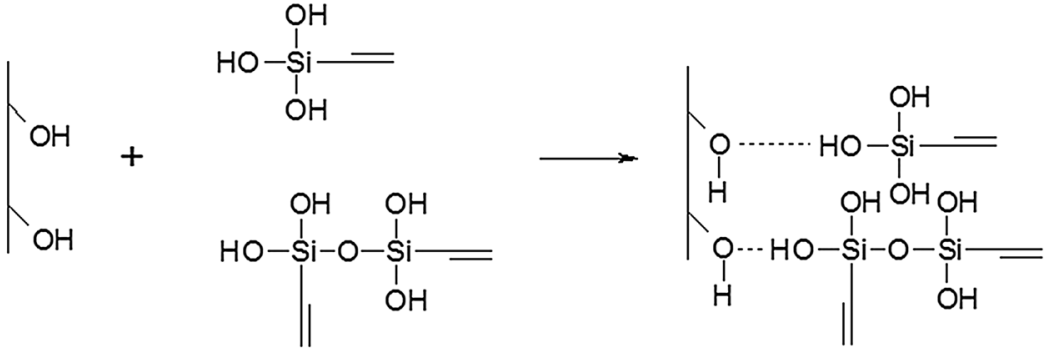

4)

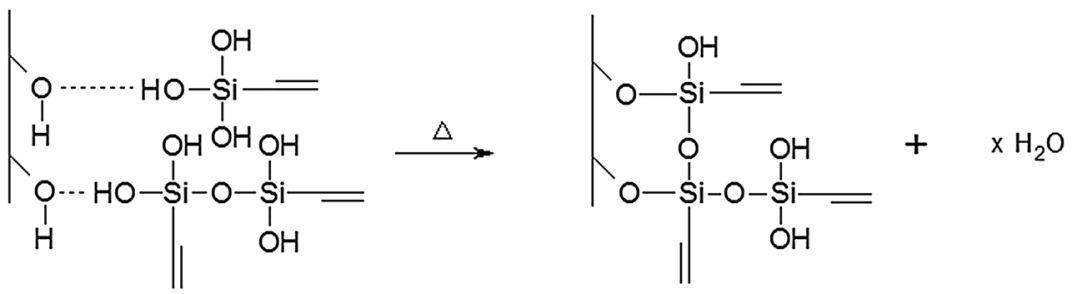

Fig. 3 Scheme of the cellulose fibre modification with VTMS: (1) hydrolysis; (2) condensation; (3) adsorption; (4) and chemical grafting [27]

On the basis of the gathered data thermal degradation steps, activation energies have been calculated with Broido [50] and Coats [51] methods in order to assess thermal stability of the prepared samples.

Table 1 Tabularized parameters of the chemical modifications in solution

\begin{tabular}{llll}
\hline Ingredients & Modification in solution & Drying process & Storage conditions \\
\hline VTMS & Evaporator: $40{ }^{\circ} \mathrm{C}$, & I step: & Dryer: $40{ }^{\circ} \mathrm{C}$ \\
Cellulose ARBOCEL & $60 \mathrm{r} / \mathrm{min}, 4 \mathrm{~h}$ & Vacuum oven: $24 \mathrm{~h}, 40{ }^{\circ} \mathrm{C}$, & \\
UFC100 & & $170 \mathrm{mbar}$ & \\
Ethanol & & II step: & \\
& & Dryer: $48 \mathrm{~h}, 120{ }^{\circ} \mathrm{C}$ \\
MA & Evaporator: $40{ }^{\circ} \mathrm{C}$, & Vacuum oven: $4 \mathrm{~h}, 100{ }^{\circ} \mathrm{C}$, \\
Cellulose ARBOCEL & $60 \mathrm{r} / \mathrm{min}, 2 \mathrm{~h}$ & $170 \mathrm{mbar}$ \\
UFC100 & & \\
Acetone & & \\
\hline
\end{tabular}




\section{Differential scanning calorimetry}

Differential scanning calorimetry (DSC) investigation has been performed in a temperature range from -50 to $300{ }^{\circ} \mathrm{C}$ prior to analyse enthalpy changes $(\Delta \mathrm{H})$ during thermal decomposition of cellulose. Here, as well, Mettler Toledo ${ }^{\circledR}$ TGA/ DSC 1 STAR $^{\text {e }}$ System equipped with Gas Controller GC10 has been employed.

\section{Dynamic light scattering}

Measurements of the particle sizes of cellulose UFC100 were taken using aqueous dispersion of the samples (0.1 g of the powder per $200 \mathrm{ml}$ of distilled water). These solutions were subjected to ultrasound for $30 \mathrm{~min}$, and the dispersion samples were poured into colorimetric cuvettes [29]. ZetaSizer Nano-S90 from Malvern Instruments has been employed.

\section{Results and discussion}

\section{FTIR analysis}

The vibrational spectra of the cellulose fibres exhibit observable band changes depending on the kind of modification conducted. Their analysis provides valuable information and helps to suggest the cellulose changes after maleic anhydride (MA) and vinyltrimethoxysilane (VTMS) grafting.

Considering Figs. 2, 3 and the results from other scientific studies, visible changes were observed. For the modification performed with the use of MA, the increased intensity of the absorption bands related to the $\mathrm{C}-\mathrm{O}, \mathrm{C}=\mathrm{O}$ and $\mathrm{C}=\mathrm{C}$ bonds was observed [30]. In contrast, the cellulose treated with VTMS indicated signals of the chemical groups containing silicon atoms [31, 32] and $\mathrm{C}=\mathrm{C}$ bonds. In addition, in both cases, a decrease in the intensity of the absorption band of the $-\mathrm{OH}$ moieties was observed as a result of the creation of ester and $\mathrm{Si}-\mathrm{O}$ bonds. Visible absorption bands may also have their origin from unreacted reagents adsorbed on the cellulose fibres surface.

Taking a closer look at Fig. 4, the absorption band at $3332 \mathrm{~cm}^{-1}$ was assigned to the $\mathrm{O}-\mathrm{H}$ stretching vibrations that occurred due to both the water and $\mathrm{O}-\mathrm{H}$ moiety content in the sample. The broadband in the $3600-3100 \mathrm{~cm}^{-1}$ region also provided considerable information concerning the presence of hydrogen bonds [33]. Moving further, the absorption band at $2894 \mathrm{~cm}^{-1}$ was connected to the $\mathrm{C}-\mathrm{H}$ stretching vibrations coming from the cellulose fibres. These two peaks have been observed in many other works $[34,35]$. Each of the performed modifications contributed to the decrease in the intensity of those absorption bands, compared to the initial cellulosic samples, and, thus, also to the lower concentration of the $\mathrm{O}-\mathrm{H}$ and $\mathrm{C}-\mathrm{H}$ moieties in these two samples.

As for the maleinization reaction of cellulose, some new signals were observed. The stretching vibration at $1719 \mathrm{~cm}^{-1}$ was assigned to the $\mathrm{C}=\mathrm{O}$ bond [35], and 

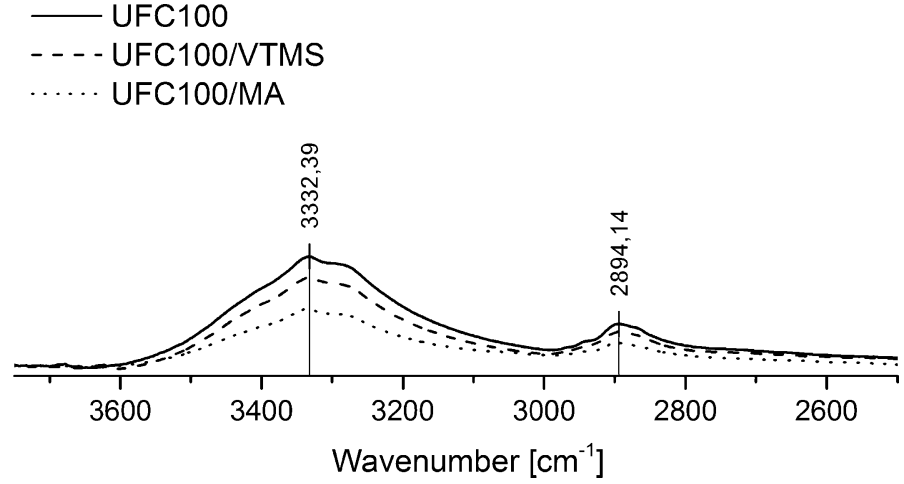

Fig. 4 FTIR spectra of the cellulose $\left(4000-2500 \mathrm{~cm}^{-1}\right)$ and absorption bands characteristic of the cellulose fibres: $3332 \mathrm{~cm}^{-1}\left(\mathrm{O}-\mathrm{H}\right.$, adsorbed water) and $2894 \mathrm{~cm}^{-1}(\mathrm{C}-\mathrm{H})$

the peak in the range of $1640-1618 \mathrm{~cm}^{-1}$ corresponds to the aldehydic and carboxyl stretching vibrations [26] or even to the adsorbed water, which was also identified in a few other studies [36]. According to Fig. 5, the presence of those moieties confirms the occurrence of new functional groups on the cellulose fibres surface. Moreover, an increase in the intensity of the absorption in the range of 1300-1200 $\mathrm{cm}^{-1}$ [37] and 900-800 $\mathrm{cm}^{-1}$ was observed, which was due to the increased concentration of the $\mathrm{C}-\mathrm{H}, \mathrm{C}=\mathrm{O}$ and $\mathrm{C}-\mathrm{O}-\mathrm{C}$ bonds. Nevertheless, a decrease in the intensity in the range between 1150 and $1000 \mathrm{~cm}^{-1}$ was observed; the $1104 \mathrm{~cm}^{-1}$ band was attributed to the asymmetric in-phase ring vibrations, $1030 \mathrm{~cm}^{-1}$ was assigned to the $\mathrm{C}-\mathrm{O}-\mathrm{C}$ vibrations, and $1046-1043 \mathrm{~cm}^{-1}$ was attributed to the $\mathrm{C}-\mathrm{C}, \mathrm{C}-\mathrm{O}-\mathrm{H}, \mathrm{C}-\mathrm{H}$ and side group vibrations [38].

The modification with the use of the silane coupling agent was not as easy to confirm as the maleinization reaction due to the overlapping effect of absorption bands. The absorption bands visible in Figs. 5 and 6, which correspond to the $\mathrm{C}-\mathrm{O}$ and $\mathrm{C}-\mathrm{C}$ stretching vibrations and $\mathrm{CH}_{2}$ rocking vibration at $1161-895 \mathrm{~cm}^{-1}$, also correspond to the $\mathrm{Si}-\mathrm{O}-\mathrm{Si}\left(1100 \mathrm{~cm}^{-1}, 950-800 \mathrm{~cm}^{-1}\right)$, $\mathrm{Si}-\mathrm{O}-\mathrm{C}\left(1450 \mathrm{~cm}^{-1}\right), \mathrm{Si}-\mathrm{OH}\left(\sim 900 \mathrm{~cm}^{-1}\right)$ and C-Si-C bonds $\left(663 \mathrm{~cm}^{-1}\right)$ [39, $40]$. The phenomenon of overlapping in the case of the silanization of the cellulose fibres was also observed in previous studies [41].

However, a few shifts in the absorption bands to lower and higher wavenumbers were noted, in which comparison is shown in Fig. 7, e.g. $-\mathrm{OH}$ stretching vibration at $3332 \mathrm{~cm}^{-1}, \mathrm{C}-\mathrm{H}$ stretching vibration at $3894 \mathrm{~cm}^{-1}, \mathrm{C}-\mathrm{O}-\mathrm{C}$ and side group vibrations at $897 \mathrm{~cm}^{-1}$, and $\mathrm{C}-\mathrm{OH}$ out-of-plane bending at $558 \mathrm{~cm}^{-1}$. They could be caused by the interactions between the adsorbed and grafted silane and maleic anhydride functional groups, which are mainly polar, with infrared irradiation.

The FTIR absorption band at $1428 \mathrm{~cm}^{-1}$, visible in Fig. 5, that was assigned to the symmetric $\mathrm{CH}_{2}$ bending vibration decreased. Its intensity, in comparison with the reference sample, reflects a possible reduction in the degree of the crystallinity of the sample modified with VTMS. This phenomenon was clearly described in detail in previous studies concerning the crystalline structures of cellulose fibres [33]. 


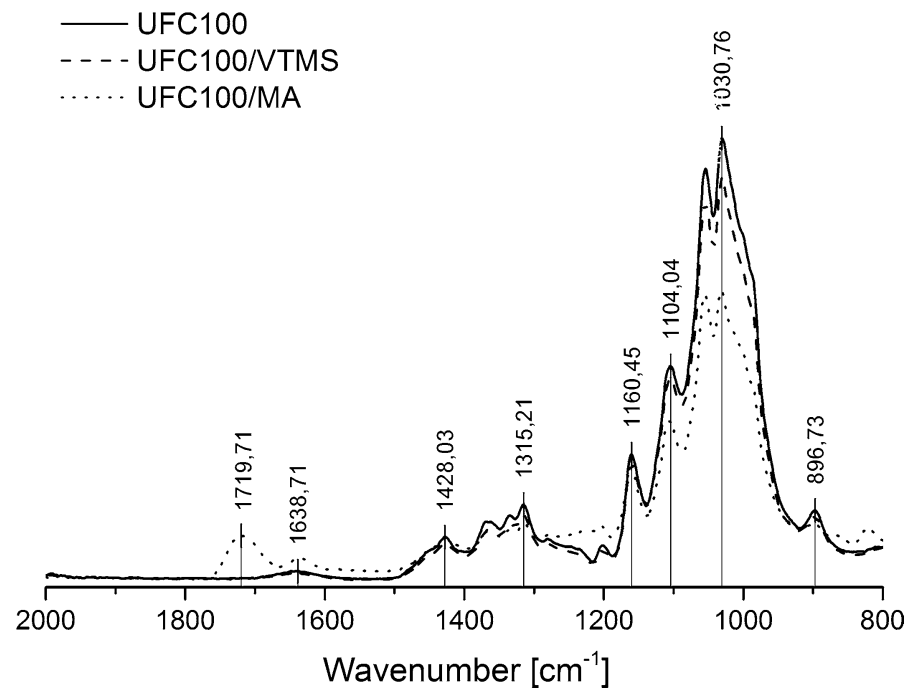

Fig. 5 FTIR spectra of the cellulose $\left(2000-800 \mathrm{~cm}^{-1}\right)$; the visible moieties characteristic of MA: $1719 \mathrm{~cm}^{-1}, 1638 \mathrm{~cm}^{-1}(\mathrm{C}=\mathrm{O}), 1046-1043 \mathrm{~cm}^{-1}(\mathrm{C}-\mathrm{C}, \mathrm{C}-\mathrm{OH}, \mathrm{C}-\mathrm{H})$ and $1030 \mathrm{~cm}^{-1}(\mathrm{C}-\mathrm{O}-\mathrm{C})$; and the overlapping phenomenon in the case of VTMS: $1161-895 \mathrm{~cm}^{-1}(\mathrm{C}-\mathrm{C}, \mathrm{C}-\mathrm{O}), 1110 \mathrm{~cm}^{-1}$ and $850-$ $800 \mathrm{~cm}^{-1}(\mathrm{Si}-\mathrm{O}-\mathrm{Si})$

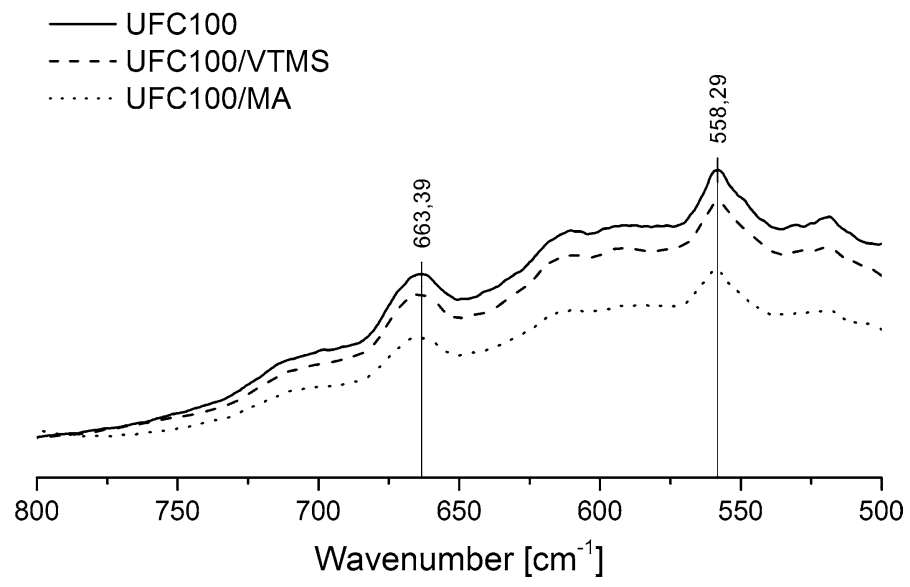

Fig. 6 FTIR spectra of the cellulose $\left(800-500 \mathrm{~cm}^{-1}\right)$ and modification with the use of VTMS reflected by the absorption band at $663 \mathrm{~cm}^{-1}(\mathrm{C}-\mathrm{Si}-\mathrm{C})$

\section{DLS investigation}

DLS analysis is a technique that can provide valuable information in order to confirm the occurrence of a modification process. It provides data regarding the hydrodynamic radii, which have been carefully described in previous studies [42, 43]. Here, the particle size changes may indicate the effect of performed treatments. 


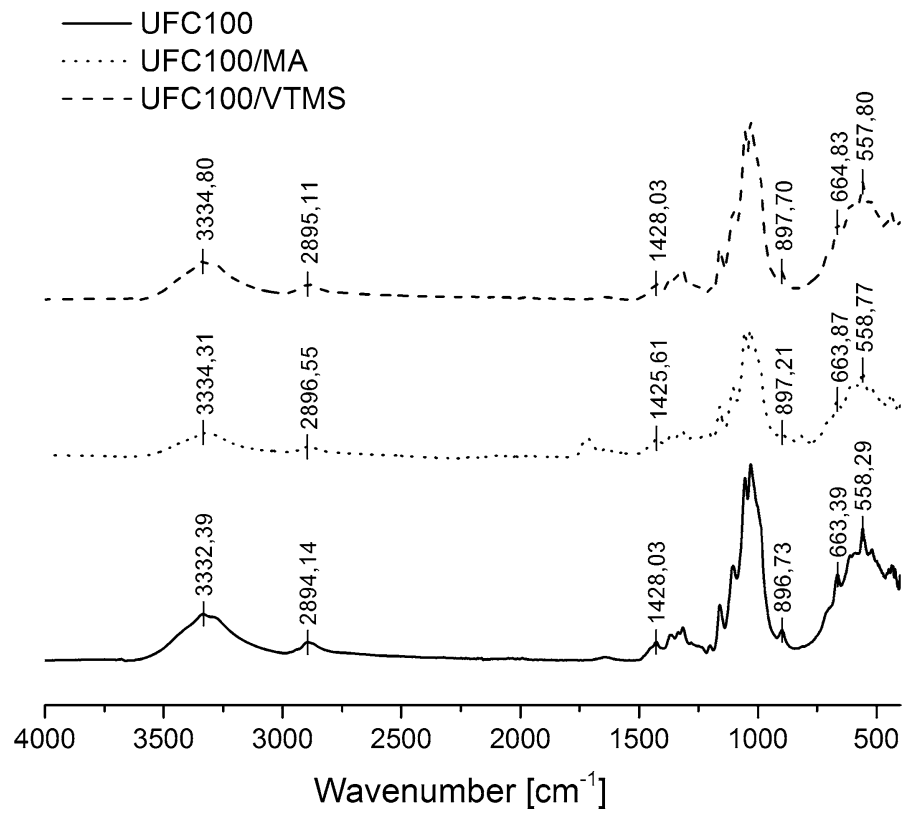

Fig. 7 Wavenumber shifts visible in the FTIR spectra that were caused by the interactions between the macromolecules

According to Table 2, it can be seen that the size of the particles changed depending on the employed modifier. The biggest particles were obtained with the use of maleic anhydride. However, in both cases, an increase in the hydrodynamic radius was observed, which proves that grafting occurred on the surface of the cellulose fibres (Fig. 8).

However, the creation of clusters and chain entanglements is possible. The influence of the concentration on these phenomena has been widely described [44]. Despite the fact that the exact radii values of the cellulose fibres might have been not known due to the aggregation processes, the results of the DLS investigation provided more details about their affinity to one another concerning the chemical groups on their surface and the surface free energy of the cellulose. The bigger are observed particles, the better affinity and possible treatment effect on particle interactions.

\section{TGA analysis}

A thermogravimetric investigation was conducted in order to define the changes in the thermal decomposition of the cellulose fibres. Many studies have been conducted on this topic $[45,46]$.

Considering Fig. 9, the first mass loss of each material was attributed to the release of water and volatile matter $[47,48]$ up to $150{ }^{\circ} \mathrm{C}$. The decreases in the mass values at this stage for neat UFC100, UFC100/VTMS and UFC100/MA were 
Table 2 Acute values of the cellulose fibre sizes

\begin{tabular}{ll}
\hline Sample & $R_{\text {average }}(\mathrm{nm})$ \\
\hline UFC100 ref. & 1178 \\
UFC100/VTMS & 1364 \\
UFC100/MA & 1424 \\
\hline
\end{tabular}

Fig. 8 Comparison of the sizes of the cellulose fibres

$3.46 \%, 3.24 \%$ and $2.13 \%$, respectively. The second decomposition event occurred at various temperatures with the initial point originated from 150 to $250{ }^{\circ} \mathrm{C}$, depending on the type of modified material. This stage was assigned to the thermal degradation of the cellulose fibres [35]. As shown in Fig. 9, the mass loss is lower in the case of the cellulose modified with MA (87.76\%) and VTMS (87.94\%), while for the neat cellulose fibres, this value is higher and equal to $92.57 \%$.

In Table 3, the data regarding the effects of modifying the cellulose with the silane VTMS and MA, representing the thermal stability of the materials, are shown. According to the first modifier, the thermal degradation of cellulose was prolonged but not as well as in the case of the modification with maleic anhydride. The use of MA resulted in an earlier onset of more intensive degradation and prolonged the whole process, which was determined from the tabularized temperature values.

The thermogravimetric analysis evidenced that the weight loss of the chemically modified cellulose fibres was lower than that of the unmodified sample, similar to other studies [26]. Moreover, the thermogravimetric curve of the neat UFC100 sample exhibited congruous parameters to the microcrystalline cellulose (MCC) thermogravimetric curve described by other scientists [49].

Activation energies of thermal decomposition steps have been established with Broido [50] and Coats [51] methods as it has been shown in various researches 


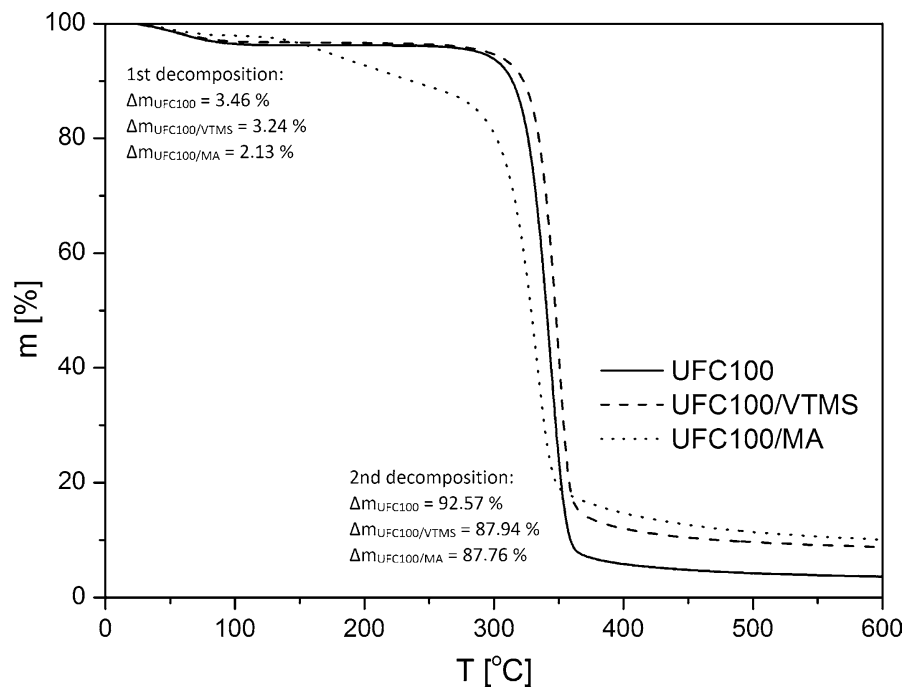

Fig. 9 TGA curves of the cellulose. The first decomposition stage is assigned to the evaporation of water and the remaining unreacted modifiers. The second mass loss is attributed to the thermal degradation of the cellulose

Table 3 Temperatures of the mass loss

\begin{tabular}{llllll}
\hline Sample & $T_{5 \%}\left({ }^{\circ} \mathrm{C}\right)$ & $T_{10 \%}\left({ }^{\circ} \mathrm{C}\right)$ & $T_{15 \%}\left({ }^{\circ} \mathrm{C}\right)$ & $T_{50 \%}\left({ }^{\circ} \mathrm{C}\right)$ & $T_{90 \%}\left({ }^{\circ} \mathrm{C}\right)$ \\
\hline UFC100 & 289 & 314 & 322 & 340 & 359 \\
UFC100/VTMS & 295 & 322 & 330 & 347 & 472 \\
UFC100/MA & 170 & 236 & 286 & 329 & 599 \\
\hline
\end{tabular}

$T_{x \%}$-temperature at which the mass loss is $x \%$

[52-54]. Obtained values are in well correspondence and are confirmed in the literature [55].

According to the results presented in Table 4, it may be concluded that the lowest value of first thermal decomposition activation energy is observed in case of the sample treated with maleic anhydride which confirms previously observed significant decrease in $T_{5 \%}$. UFC100/MA occurs to be the specimen of poor thermal stability.

On the other hand, modification with VTMS contributes to an increase of 1st step $E_{\mathrm{a}}$ in comparison with the reference sample. Consequently, UFC100/VTMS thermal resistance has been improved. Similar trends are observed considering 2nd decomposition step. 
Table 4 Activation energies of thermal degradation steps calculated according to Broido [50] and Coats method [51]

\begin{tabular}{|c|c|c|c|c|}
\hline \multirow{3}{*}{$\begin{array}{l}\text { Sample } \\
\text { UFC100 }\end{array}$} & \multicolumn{4}{|c|}{ Activation energy $E_{\mathrm{a}}(\mathrm{kJ} / \mathrm{mol})$} \\
\hline & \multicolumn{2}{|c|}{ Broido method } & \multicolumn{2}{|c|}{ Coats method } \\
\hline & 1st step & $101 \pm 4$ & 1st step & $103 \pm 1$ \\
\hline & 2nd step & $258 \pm 9$ & 2nd step & $254 \pm 3$ \\
\hline \multirow[t]{2}{*}{ UFC100/VTMS } & 1st step & $108 \pm 4$ & 1st step & $109 \pm 1$ \\
\hline & 2nd step & $280 \pm 10$ & 2nd step & $275 \pm 5$ \\
\hline \multirow[t]{2}{*}{ UFC100/MA } & 1st step & $85 \pm 5$ & 1st step & $81 \pm 1$ \\
\hline & 2nd step & $230 \pm 10$ & 2nd step & $234 \pm 5$ \\
\hline
\end{tabular}

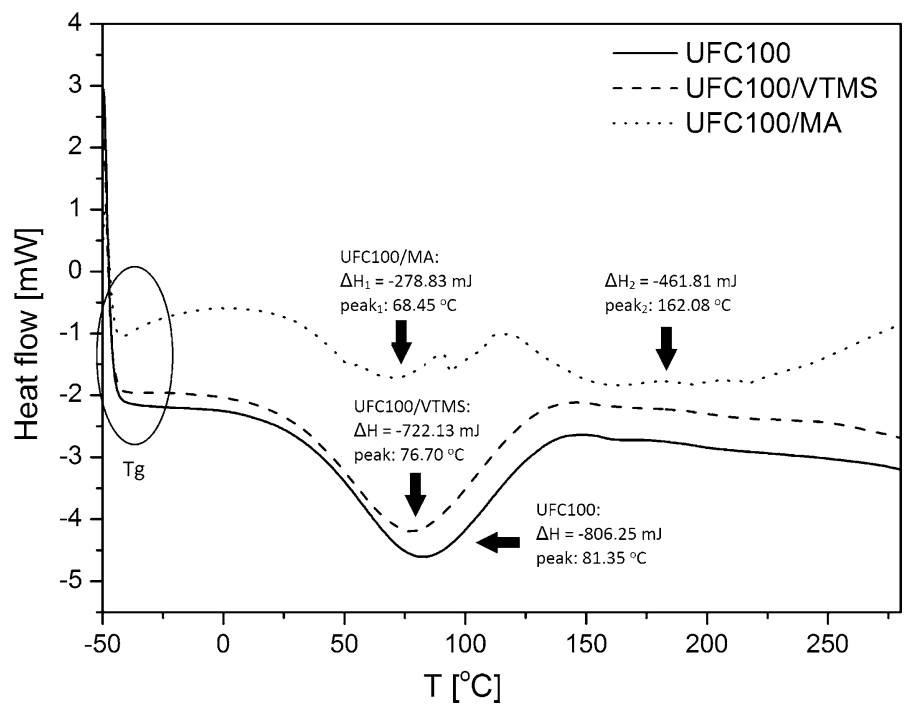

Fig. 10 DSC analysis of the cellulose samples. Visible changes during the process of evaporation of the adsorbed water and thermal decomposition of the cellulose fibres

\section{DSC investigation}

Thermograms reveal some details about the water evaporation from the cellulose surface and fibres initial thermal decomposition [56]. The DSC analysis revealed that even at $100{ }^{\circ} \mathrm{C}$, completely dried cellulose was not obtained. These data show how troublesome it is to achieve the full desorption of water from the surface of hydrophilic fillers. This problem was also mentioned in other studies $[57,58]$ that evaluated the effect of water content on the glass transition temperature.

According to Fig. 10, the $T_{\mathrm{g}}$ of all samples is near the region of $-40{ }^{\circ} \mathrm{C}$, which, according to another study [59], indicates that the water content in the specimens, surprisingly, could be even approximately $17 \%$. Nevertheless, no significant changes between the specimens, considering $T_{\mathrm{g}}$, have been noted. 
The endothermic peaks at about $80{ }^{\circ} \mathrm{C}$ were strengthened as a consequence of the evaporation of water and the inner volatile substances. The shifts in the peaks to lower temperatures of the modified samples in comparison with the reference samples should be emphasized-from $81.35{ }^{\circ} \mathrm{C}$ (UFC100 ref.) to $76.70{ }^{\circ} \mathrm{C}$ (UFC100/ VTMS) and $68.45^{\circ} \mathrm{C}$ (UFC100/MA). Furthermore, the changes in the enthalpy also varied. The highest value was observed in the case of the neat cellulose fibres. A similar effect was observed in another study and was described as a result of the increase in the length-to-diameter ratio during the performed modification. Therefore, according to the authors, the evaporation of moisture was facilitated [60] which contributed to the fall in enthalpy values.

In conjunction with Fig. 10, thermal degradation prolongation, in case of cellulose treated with maleic anhydride, a second endothermic peak, of a higher enthalpy value, can be observed at $162.08{ }^{\circ} \mathrm{C}$. This may be connected with more complex thermal degradation of MA. Inasmuch as the earlier decomposition of the fibre is visible in the DSC curve, the data provide a perfect confirmation of phenomenon observed in TGA-poor thermal stability of UFC100/MA in comparison with UFC100/VTMS.

\section{Conclusions}

The samples have been characterized primarily from IR data. The FTIR spectra revealed that the chemical modification of the cellulose was successful. The absorption bands at $1719 \mathrm{~cm}^{-1}\left(\mathrm{C}=\mathrm{O}\right.$ stretching vibrations) and $1638 \mathrm{~cm}^{-1}$ (aldehydic and carboxyl stretching vibrations) originated from the maleic anhydride grafted on the surface of the fibres. In the case of the silanization reaction, the shifts in the wavenumbers and the intensity decrease at $1428 \mathrm{~cm}^{-1}$ were crucial. They indicated, not only, different interactions between the functional groups of the cellulose with the adsorbed and grafted silane but also information regarding the decrease in the degree of crystallinity. Nevertheless, possible signals from unreacted modifiers observed in FTIR spectra have to be considered.

The DLS investigation proved that the modified fillers had a bigger size in comparison with unmodified sample, and the thermogravimetric analysis evidenced that the weight loss of the chemically modified cellulose fibres was lower. Moreover, the various onset times of the chemical decomposition of the inner specimens were noted and confirmed with both TGA and DSC investigations. The best improvement in thermal resistance, according to activation energy calculations, has been detected in case of VTMS treated cellulose fibres.

All things gathered, performed modifications have affected cellulose structure as well as its thermal properties. Prepared filler may be added to the polymer matrix in order to create various green composites finding application, e.g. in packaging or automotive industry, which is of a high importance considering its higher biodegradation potential. Moreover, given fibres treatment result analysis, universal approach allows to describe chemical modification impact at many levels. 
Open Access This article is distributed under the terms of the Creative Commons Attribution 4.0 International License (http://creativecommons.org/licenses/by/4.0/), which permits unrestricted use, distribution, and reproduction in any medium, provided you give appropriate credit to the original author(s) and the source, provide a link to the Creative Commons license, and indicate if changes were made.

\section{References}

1. Rodionova G, Lenes M, Eriksen $\varnothing$, Gregersen $\varnothing$ (2011) Surface chemical modification of microfibrillated cellulose: improvement of barrier properties for packaging applications. Cellulose 18:27-134

2. Dufresne A, Belgacem M (2013) Cellulose-reinforced composites: from micro- to nanoscale. Polimeros 23:277-286

3. Klemm D, Schumann D, Kramer F, Heßler N, Koth D, Sultanova B (2009) Nanocellulose materials—different cellulose, different functionality. Macromol Symp 280:60-71

4. Gardner D, Oporto G, Mills A, Samir M (2008) Adhesion and surface issues in cellulose and nanocellulose. J Adhes Sci Technol 22:545-567

5. Moushiul Alam AKM, Beg MDH, Reddy Prasad DM, Kham MR, Mina MF (2012) Structures and performances of simultaneous ultrasound and alkali treated oil palm empty fruit bunch fiber reinforced poly(lactic acid) composites. Part A. Appl Sci Manuf 43:1921-1929

6. Mwaikambo LY, Ansell MP (2002) Chemical modification of hemp, sisal, jute, and kapok fibres by alkalization. J Appl Polym Sci 84:2222-2234

7. Varshney VK, Naithani S (2011) Chemical functionalization of cellulose derived from nonconventional sources. In: Kalia $\mathrm{S}$ et al (eds) Cellulose fibers: bio and nano-polymer composites. Springer, Berlin, pp 43-60

8. Saputra AH, Qadhayna L, Pitaloka AB (2014) Synthesis and characterization of carboxymethyl cellulose (cmc) from water hyacinth using ethanol-isobutyl alcohol mixture as the solvents. IJCEA 5:36-40

9. Joshi G, Naithani S, Varshney VK, Bisht SS, Rana V, Gupta PK (2015) Synthesis and characterization of carboxymethyl cellulose from office waste paper: a greener approach towards waste management. Waste Manag 38:33-40

10. Barthel S, Heinze T (2006) Acylation and carbanilation of cellulose in ionic liquids. Green Chem 8:301-306

11. Heinze T, Schwikal K, Barthel S (2005) Ionic liquids as reaction medium in cellulose functionalization. Macromol Biosci 5:520-525

12. Wendler F, Kosan B, Krieg M, Meister F (2009) Possibilities for the physical modification of cellulose shapes using ionic liquids. Macromol Symp 280:112-122

13. Edgar K, Heinze T, Liebert T (2009) Cellulose solvents: for analysis, shaping and chemical modification. American Chemical Society, Washington

14. Wu J, Zhang J, Zhang H, He J, Ren Q, Guo M (2004) Homogeneous acetylation of cellulose in a new ionic liquid. Biomacromolecules 5:266-268

15. Liu S, Sun G (2008) Radical graft functional modification of cellulose with allyl monomers: chemistry and structure characterization. Carbohydr Polym 71:614-625

16. Dahou W, Ghemati D, Oudia A, Aliouche D (2010) Preparation and biological characterization of cellulose graft copolymers. Biochem Eng J 48:187-194

17. Kamel S, Ali N, Jahangir K, Shah SM, El-Gendy AA (2008) Pharmaceutical significance of cellulose: a review. Express Polym Lett 2:758-778

18. Narita M, Tabata M, Yoshida A (2007) Methods for preparing alkali cellulose and cellulose ether. US 0149774A1

19. Odian G (2004) Principles of polymerization. Wiley, Hoboken

20. Zhang X, Wang F, Keer LM (2015) Influence of surface modification on the microstructure and thermo-mechanical properties of bamboo fibers. Materials 8:6597-6608

21. O'Connell DW, Birkinshaw C, O'Dwyer TF (2008) Heavy metal adsorbents prepared from the modification of cellulose: a review. Bioresour Technol 99:6709-6724

22. Wan Ngah WS, Hanafiah MALM (2008) Removal of heavy metal ions from waste water by chemically modified plant wastes as adsorbents: a review. Bioresour Technol 99:3935-3948 
23. Hokkanen S, Bhatnagar A, Sillanpaa M (2016) A review on modification methods to cellulosebased adsorbents to improve adsorption capacity. Water Res 91:156-173

24. Zhou F, Cheng G, Jiang B (2014) Effect of silane treatment on microstructure of sisal fibers. Appl Surf Sci 292:806-812

25. Teaca CA, Bordiliau R, Spiridon I (2014) Maleic anhydride treatment of soft wood—effect on wood structure and properties. Cellul Chem Technol 42:863-868

26. Bodirlau R, Teaca CA (2009) Fourier transform infrared spectroscopy and thermal analysis of lignocellulose fillers treated with organic anhydrides. Rom J Phys 54:93-104

27. Yanjun X, Callum ASH, Zefang X, Holger M, Carsten M (2010) Silane coupling agents used for natural fiber/polymer composites: a review. Composites 41:806-819

28. Song J, Rojas OJ (2013) Approaching super-hydrophobicity from cellulosic materials: a review. NPPRJ 28:216-238

29. Oberlerchner JT, Rosenau T, Potthast A (2015) Overview of methods for the direct molar mass determination of cellulose. Molecules 20:10313-10341

30. Wibowo AC, Desai SM, Mohanty AK, Drzal LT, Misra M (2006) A solvent free graft copolymerization of maleic anhydride onto cellulose acetate butyrate bioplastic by reactive extrusion. Macromol Mater Eng 291:90-95

31. Hassan MM, Khan MA (2008) Role of N-( $\beta$-amino ethyl) $\gamma$-aminopropyl trimethoxy silane as coupling agent on the jute-polycarbonate composites. Polym Plast Technol Eng 47:847-850

32. Pacheco DM, Johnson JR, Koros WJ (2012) Aminosilane-functionalized cellulosic polymer for increased carbon dioxide sorption. Ind Eng Chem Res 51:503-514

33. Ciolacu D, Ciolacu F, Popa VI (2011) Amorphous cellulose-structure and characterization. Cellul Chem Technol 45:13-21

34. Li Y, Xiao J, Chen M, Song Z, Yi Z (2014) Absorbents based on maleic anhydride-modified cellulose fibers/diatomite for dye removal. J Mater Sci 49:6696-6704

35. Zhang W, Li C, Liang M (2010) Preparation of carboxylate-functionalized cellulose via solvent-free mechanochemistry and its characterization as a biosorbent for removal of $\mathrm{Pb}^{2+}$ from aqueous solution. J Hazard Mater 181:468-473

36. Sheltami RM, Kargarzadeh H, Abdullah I (2015) Effects of silane treatment of cellulose nanocrystals on tensile properties of cellulose polyvinyl chloride nanocomposite. Sains Malays 44:801-810

37. Proniewicz LM, Paluszkiewicz C, Weselucha-Birczynska A, Majcherczyk H, Baranski A, Konieczna A (2001) FT-IR and FT-Raman study of hydrothermally degraded cellulose. J Mol Struct 596:1-3

38. Mizi F, Dasong D, Biao H (2012) Fourier transform infrared spectroscopy for natural fibres. In: Salich S (ed) Fourier transform-materials analysis. InTech, Rijeka

39. Thakur MK, Gupta RK, Thakur VK (2014) Surface modification of cellulose using silane coupling agent. Carbohydr Polym 111:849-855

40. Abdelmouleh M, Boufi S, Salah A, Belgacem MN, Gandini A (2002) Interaction of silane coupling agents with cellulose. Langmuir 18:3203-3208

41. Loof D, Hiller M, Oschkinat H, Koschek K (2016) Quantitative and qualitative analysis of surface modified cellulose utilizing TGA-MS. Materials 9:415-428

42. Oberlerchner JT, Rosenau T, Potthast A (2015) Overview of methods for the direct molar mass determination of cellulose. Molecules 20:10313-10341

43. Pamies R, Zhu K, Kjoniksen AL, Nystrom B (2009) Thermal response of low molecular weight poly-( $\mathrm{N}$-isopropylacrylamide) polymers in aqueous solution. Polym Bull 62:487-502

44. Luo C, Wang S, Liu H (2007) Cellulose conversion into polyols catalysed by reversibly formed acids and supported ruthenium clusters in hot water. Angew Chem Int Ed 46:7636-7639

45. Das K, Ray D, Bandyopadhyay NR, Sengupta S (2010) Study of the properties of microcrystalline cellulose particles from different renewable resources by XRD, FTIR, Nanoindentation, TGA and SEM. J Polym Environ 18:355-363

46. Yang H, Yan R, Chen H, Lee DH, Zheng C (2007) Characteristics of hemicellulose, cellulose and lignin pyrolysis. Fuel 86:12-13

47. Ma S, Yu SJ, Wang ZH (2013) Ultrasound-assisted modification of beet pulp cellulose with phthalic anhydride in ionic liquid. Cellul Chem Technol 47:527-533

48. Wysau G, Gimba CE, Agbaji EB, Ndukwe GI (2016) Thermo-gravimetry (TGA) and DSC of thermal analysis techniques in production of active carbon from lignocellulosic materials. Adv Appl Sci Res 7:109-115 
49. Feng-Yuan H (2012) Thermal properties and thermal degradation of cellulose tri-stearate (CTs). Polymers 4:1012-1024

50. Broido A (1969) A simple, sensitive graphical method of treating thermogravimetric analysis data. J Polym Sci 7:1761-1773

51. Coats AW, Redfern JP (1964) Kinetic parameters from thermogravimetric data. Nature 201:68-69

52. Shekh MI, Patel DM, Patel NN, Patel US, Patel KP, Patel RM (2018) Methacrylate copolymers and their composites with nano-CdS: synthesis, characterization, thermal behavior, and antimicrobial properties. IJIC 9:153-166

53. Shekh MI, Patel DM, Patel KP, Patel RM (2016) Electrospun nanofibers of poly(NPEMA-co.CMPMA): used as heavy metal ion remover and water sanitizer. Fiber Polym 17:358-370

54. Shekh MI, Patel NN, Patel KP, Patel RM, Ray A (2017) Nano silver-embedded electrospun nanofiber of poly(4-chloro-3-methylphenyl methacrylate) use as water sanitizer. Environ Sci Pollut Res 24:5701-5716

55. Huang FY (2012) Thermal properties and thermal degradation of cellulose tri-stearate (CTs). Polymers 4:1012-1024

56. Moshiul Alam AKM, Beg MDH, Mina MF, Mamun AA, Bledzki AK (2015) Degradation and stability of green composites fabricated from oil palm empty fruit bunch fiber and polylactic acid: effect of fiber length. J Compos Mater 49:3103-3114

57. Ford JL (1999) Thermal analysis of hydroxypropylmethylcellulose and methylcellulose: powders, gels, matrix tablets. Int J Pharm 179:209-228

58. Picker KM, Hoag SW (2002) Characterization of the thermal properties of microcrystalline cellulose by modulated temperature differential scanning calorimetry. J Pharm Sci 91:342-349

59. Szczesniak L, Rachocki A (2008) Glass transition temperature and thermal decomposition of cellulose powder. Cellulose 15:445-451

60. Zhang X, Wang F, Keer LM (2015) Influence of surface modification on the microstructure and thermo-mechanical properties of bamboo fibers. Materials 8:6597-6608

\section{Affiliations}

\section{Stefan Cichosz ${ }^{1} \cdot$ Anna Masek $^{1}$ (D) Korneliusz Wolski ${ }^{1}$ Marian Zaborski ${ }^{1}$}

Anna Masek

anna.masek@p.lodz.pl

1 Faculty of Chemistry, Institute of Polymer and Dye Technology, Lodz University of Technology, Stefanowskiego 12/16, 90-924 Lodz, Poland 